\title{
AUTORES ARCHIVISTAS Y ESCRITORES DESDOBLADOS EN LA SEMILLA DE LA IRA DE CONSUELO TRIVIÑO ANZOLA Y LA OTRA SELVA DE BORIS SALAZAR
}

\author{
POR \\ KEVIN GuERRIERI \\ University of San Diego
}

Asími vida es una fugay todo lo pierdoy todo es del olvido, o del otro. No sé cuál de los dos escribe esta página. Jorge Luis Borges, "Borges y yo" (62)

En el décimotercer capítulo de la novela La semilla de la ira de Consuelo Triviño titulado "A las puertas de İ́taca (1924)", el narrador intradiegético, José María Vargas Vila, describe su viaje de regreso a Colombia después de casi cuatro décadas en el exilio. Tras una breve estancia en Barranquilla, donde "la multitud se agolpa a las puertas del hotel para darme la bienvenida" (Triviño 201), el escritor emprende un viaje clandestino a Bogotá con el fin de visitar la tumba de su madre. Deseando permanecer en el anonimato, el viajero usa el pretexto de una terrible desfiguración para taparse el rostro con un lienzo y así evitar que se lo reconozca. Disfrazado de esta manera, a bordo de un buque de vapor que sube por el río Magdalena, Vargas Vila se pone en contacto con personajes variopintos que incluyen, por un lado, un "joven romántico" que habla obsesivamente de José Eustasio Rivera, quien acaba de publicar La vorágine (1924) -"Nada más lejos de mí que rebajar mi arte a la crónica periodística", reflexiona el narrador con desprecio-y, por el otro, un alcohólico que "se empeñaba en afirmar que el divino Vargas Vila era el escritor más grande de América" (212).

En este episodio anecdótico-que nace de la imaginación de la autora-se vislumbran algunos de los ejes temáticos que atraviesan la novela de Consuelo Triviño Anzola, publicada en 2008 y que incluyen la compleja relación que Vargas Vila mantenía desde el exilio con su patria, la fama e infamia que rodeaba en todas partes a esta figura controvertida y la constante (auto)valoración de su obra novelística frente a la hegemonía cultural nacional. No sobra señalar aquí que al lado de Rivera, quien ocupa un lugar destacado en las letras latinoamericanas, Vargas Vila es una figura sumamente enigmática, ya que en aquel entonces era un best seller en lengua española a nivel 
internacional y al mismo tiempo un escritor maldito y marginado en su patria. ${ }^{1}$ Rivera se suele catalogar como el autor que escribió una novela de la tierra fundacional y Vargas Vila, en cambio, se percibe como un panfletista político exiliado que ganó renombre escribiendo, prolíficamente, novelas subversivas de poca calidad literaria. En lugar de recurrir al desgastado binomio de lo canónico y lo marginado, sin embargo, conviene adoptar aquí el concepto del archivo, tal y como Juan Carlos González Espitia lo concibe: equiparándolo con el suplemento derridiano, el autor plantea la idea del "carnero" como zona que coexiste con el "archivo abierto", la zona pública y expuesta del archivo, en la cual se ubican los textos descartados (18-23). Lo importante es la relación orgánica e interdependiente que existe entre el carnero y el archivo abierto; en conjunto las dos zonas forman lo que es el archivo. ${ }^{2}$

Si cada estudio crítico es una reorganización efímera y provisional del archivo, tal como plantea González Espitia, lo mismo se puede postular de las dos novelas que se analizan aquí: La semilla de la ira, el diario íntimo de Vargas Vila ficcionalizado por Triviño Anzola, y La otra selva, una novela publicada en 1991 por el escritor ibaguereño Boris Salazar, en la cual se ficcionaliza la historia de la muerte de José Eustasio Rivera en Nueva York. Este artículo se centra, entonces, en analizar la función de archivista que desempeñan Triviño Anzola y Salazar en sus respectivos proyectos novelísticos; cada uno realiza una tácita labor de técnico o técnica reordenando activamente los textos del archivo y transformándolos mediante su propia poética de la novela. No se propone aquí una exploración de un diálogo intertextual ficticio que se entable entre Vargas Vila y Rivera en estas novelas, puesto que, aparte del episodio ya mencionado, está ausente. Se trata más bien de examinar el desdoblamiento de los autores, la estructura narrativa y el planteamiento estético de cada texto, a la luz de una convergencia de lo (auto)biográfico, la metaficción y la parodia dentro de estas reconfiguraciones de la historiografía literaria colombiana.

Se puede decir que toda novela abarca algo de lo autobiográfico, aunque se trate de huellas mínimas de los sucesos y experiencias vitales del autor. Tanto en el caso de Vargas Vila como en el de Rivera, sin embargo, esa continua negociación entre personaje ficticio, presencia autorial y escritor de carne y hueso cobra suma importancia. Salazar y Triviño Anzola, a su vez, vuelven más complejo aquel espacio intermedio entre la realidad empírica y los mundos ficticios al desdoblar a los autores y sus personajes,

\footnotetext{
Analizo el "fenómeno Vargas Vila" en Palabra, poder y nación: la novela moderna en Colombia de 1896 a 1927.

2 Algunos de los aspectos más destacados de esta configuración incluyen los siguientes: no existe una jerarquía ni dentro del archivo abierto o el carnero ni entre ambos; la dinámica del archivo no puede producir una institucionalización de los textos puesto que su ubicación en las zonas siempre es provisional; los movimientos y reubicaciones dentro del archivo son constantes y arbitrarios; y cada estudio crítico constituye una reorganización del archivo y como tal es perecedera (González Espitia 19-22).
}

Revista Iberoamericana, Vol. LXXXI, Núm. 252, Julio-Septiembre 2015, 837-846 ISSN 0034-9631 (Impreso) 
con lo cual se multiplican los espejos y se aumenta la ambigüedad, escamoteando el concepto de lo verídico y agudizando el efecto laberíntico. En varias ocasiones los lectores empedernidos de Vargas Vila le revisaron las manos con el fin de averiguar si el escritor las tenía quemadas como las de Flavio Durán, una creación suya, el protagonista de Lirio negro (González Espitia 78). Años después y ahora él mismo convertido en personaje ficticio de La semilla de la ira, el Vargas Vila intratextual señala que el "vulgo suele creer a pie juntillas lo que lee y sin duda me ha de haber tomado por Flavio Durán" (86). De manera contraria pero paralela, Vargas Vila cree toparse con personajes suyos en determinados momentos, como, por ejemplo, en un transatlántico atravesando el océano: "Era la primera vez que me encontraba con uno de los personajes salidos de mí, como si éstos escaparan de las páginas para exigirme la continuidad de su historia. La Witowska del barco se llamaba, o al menos eso decía, Katerina Goncharova y no sospechaba que bajo otro nombre la había eternizado en mis tragedias" (182).

Asimismo, muchos de los primeros lectores de La vorágine recibieron la novela como si fuese una obra absolutamente verídica y confundían al protagonista, Arturo Cova, con el autor de carne y hueso. En su biografía del escritor huilense, Eduardo Neale-Silva señala, por ejemplo, que un crítico español de aquel entonces estaba convencido de la existencia del manuscrito hallado del "desventurado cauchero", o sea, Cova: "resulta casi imposible ... discernir a uno u otro escritor de Colombia el lauro que la obra merece" (302). Esta confusión se debe, en gran parte, a la presentación del texto como documento, enmarcado por el prólogo, el fragmento de la carta de Cova y el epílogo, con lo cual se inscribe el autor a sí mismo precisamente en la frontera entre la realidad empírica y el mundo ficticio de la novela. Tal como señala Montserrat Ordóñez, "Rivera oscilaba entre su autocomplacencia como creador literario y su insistencia en la veracidad de su relato" (Introducción 22). Cuando aparece en La otra selva, a su vez, el autor, ahora transformado en personaje ficticio, a veces parece confundirse a sí mismo con su protagonista: "(Cosa curiosa: Rivera no quiso decir aquella noche que el hombre en la fotografía no era Cova, sino él, José Eustasio Rivera, cuando andaba por esas tierras en compañía de su amigo Franco Zapata)" (89). Los paréntesis que encierran el comentario indican que se trata de un aparte dirigido al lector por el periodista, esto es, el "espía a sueldo", quien, a su vez, se podría ver como un desdoblamiento del autor mismo.

El intertexto de La semilla de la ira y el de La otra selva no se limita a la producción novelística anterior de Vargas Vila o Rivera, respectivamente, sino que abarca la oeuvre entera del autor-protagonista, así como la obra crítica sobre el mismo y la historia de su vida relatada en textos (auto)biográficos. Entre los agradecimientos consignados al final de su novela, Triviño Anzola revela el germen del proyecto y lo que en conjunto constituye su intertexto: sus pesquisas llevadas a cabo para su tesis doctoral; sus viajes a Cuba a "rescatar" el diario íntimo de Vargas Vila; y un cuento que escribió sobre el autor en París, el cual despertó en ella "el deseo de dar vida en la ficción a este personaje"

Revista Iberoamericana, Vol. LXXXI, Núm. 252, Julio-Septiembre 2015, 837-846 ISSN 0034-9631 (Impreso)

ISSN 2154-4794 (Electrónico) 
(279). ${ }^{3}$ Una obra más que hay que tener en cuenta es una edición del mismo diario de Vargas Vila que se publicó en 2000 a cargo del cubano Raúl Salazar Pazos y que surgiera en un ambiente de intriga y escándalo, propio de cualquier texto vargasvilesco. ${ }^{4}$ Respecto a La otra selva, el intertexto lo componen principalmente La vorágine, la única novela publicada por Rivera, y el libro citado anteriormente de Neale-Silva, Horizonte humano: vida de José Eustasio Rivera, publicado en 1960 pero que, tal como advierte Álvaro Pineda Botero, sigue siendo "el estudio biográfico más completo sobre Rivera" (40). Los últimos dos capítulos, "Tras el dios becerro" y "El poeta en el recuerdo", son los que corresponden directamente al plano histórico de La otra selva ya que versan sobre la estadía del escritor en Nueva York.

Como novelistas archivistas apropiándose del intertexto, reordenando los elementos del archivo, y creando sus propias obras, Triviño Anzola y Salazar asumen dos acercamientos a su labor extremadamente distintos que se reflejan, sobre todo, en la narración y la estructura de sus novelas. La semilla de la ira comprende diecisiete capítulos titulados y fechados, cada uno con un epígrafe de Giacomo Leopardi, Víctor Hugo, Friedrich Nietzsche o Anatole France, entre otros autores cercanos a Vargas Vila sobre los que escribió en diferentes momentos. La novela se narra en primera persona y se presenta como si fuesen las memorias que Vargas Vila va escribiendo hasta el año de su muerte. La narración empieza en 1899 cuando el escritor colombiano acaba de llegar a París. Es un año significativo en varios niveles: por un lado, marca el final de un siglo y, por el otro, señala el comienzo de una nueva etapa en la carrera de Vargas Vila. Se ha iniciado el período "artístico" del escritor y su fama va en auge tras el éxito de su novela Ibis. Lo que sigue en la narrativa incluye una reconstrucción de su pasado en Colombia anterior al exilio; una recreación de algunas de las urbes europeas del momento, sobre todo, París, Roma y Barcelona; y un recorrido literario e intelectual de la época. Estas memorias ficcionalizadas abarcan más de tres décadas, hasta 1933, y el discurso se ciñe estrechamente a un modo de representación anclado precisamente en las cavilaciones del protagonista que van vinculando el pasado narrado con el tiempo presente de narración, conforme a una lógica inherente del género.

\footnotetext{
3 Para una dilucidación del proceso escritural de la obra de Triviño Anzola, ver su artículo "Vargas Vila, del mito y la leyenda a la ficción narrativa" que forma parte del presente volumen.

4 En el prólogo, titulado "Las extrañas relaciones entre García Márquez y Vargas Vila", Salazar Pazos relata la historia de cómo adquirió el manuscrito inédito del diario y lo que aconteció antes de que lograse publicarlo: afirma que las autoridades cubanas lo detuvieron y lo torturaron por haberse negado a "entregar a las autoridades el manuscrito que posee de un escritor, amigo que fue del eximio apóstol José Martí" (17). Salazar Pazos implica a García Márquez en este asunto por haber sido la única persona a la que había informado de que poseía el manuscrito; asimismo, se defiende de las acusaciones, publicadas con algunos fragmentos del diario en El Tiempo en 1989 por Triviño Anzola, de que él hubiese intentado huir de la isla llevándose el manuscrito clandestinamente. Lo más interesante de esta intriga es que tanto el diario publicado por Salazar Pazos como la novela de Triviño Anzola representan distintas "versiones" del diario original de Vargas Vila.
}

Revista Iberoamericana, Vol. LXXXI, Núm. 252, Julio-Septiembre 2015, 837-846 
En La otra selva se narra la historia de Rivera en Nueva York en 1928. A diferencia de La semilla de la ira, ésta es, tal como señala Natalia Crespo, un "mosaico lingüístico" o "una novela collage en donde la pluralidad de voces y de registros es permanente" (279). Rivera había viajado a Estados Unidos con el objetivo de hacer traducir al inglés La vorágine y también promover su adaptación al cine. Además, en aquel entonces el escritor estaba trabajando en su próxima novela, La mancha negra, que trataba el tema de la explotación del petróleo en Colombia. El título de la novela de Salazar alude claramente a la selva urbana: si bien a Arturo Cova lo devora la selva amazónica, a José Eustasio Rivera lo devora Nueva York. Compuesta de treinta fragmentos numerados, la obra tiene una estructura circular que empieza y termina en el Polyclinical Hospital, donde el escritor se está muriendo. La Nueva York de La otra selva se inscribe en dos planos temporales superpuestos, una construcción que contribuye a la complejidad de la novela. Por un lado, está la ciudad actual que corresponde al tiempo presente de la narración; sin embargo, como ya se ha indicado, no se trata de una sola voz narrativa. Además del narrador omnisciente en tercera persona, hay dos narradores más que van relatando la historia de Rivera en Nueva York muchos años después de su muerte: un inmigrante colombiano, periodista fracasado, quien escribe en una vieja máquina de escribir Underwood en un cuarto de pensión en el Bowery, y Claire Weingest, narradora en segunda persona que, sentada en un banco en la orilla del Hudson, va escribiendo su historia de amor frustrado con Rivera. El periodista, cuyo nombre nunca se revela, describe cómo fue contratado como detective privado para espiar los movimientos de Rivera y robarle el manuscrito de La mancha negra.

En La otra selva la apropiación del intertexto principal, la novela de Rivera, se basa, sobre todo, en la creación de una especie de remolino textual. Al analizar La vorágine, R. H. Moreno Durán señala que “[v]oces, ecos, polifonías, todo conforma un registro tan denso y violento como el vórtice que le da sentido a la novela" (437). Sylvia Molloy, asimismo, afirma que un "entrecruzamiento y desplazamiento de voces, exhibidos emblemáticamente en el prólogo, el epígrafe y el epílogo, se producen en toda la novela" (506). El texto de Boris Salazar, a su vez, entreteje en dicha polifonía su propia multiplicidad de voces narrativas, desdoblamientos de personajes, parodias y registros literarios. La obra constituye, de hecho, un artificio paródico multifacético con varios niveles y distancias críticas. Si bien el intertexto de una parodia siempre es una forma de discurso codificado (Hutcheon 16), en La otra selva son muchos los "blancos" escogidos por Salazar y se pueden ver como una serie de cajas chinas: el marco general es la parodia de la novela negra con la puesta en escena del personaje del periodista espía, quien se va convirtiendo en novelista a medida que nosotros, los lectores extratextuales, vamos leyendo. De ahí sigue la secuencia de parodias: tanto los personajes de La vorágine en sí como la relación que Rivera tiene con ellos; el discurso académico sobre los textos (el estudio de un profesor norteamericano); y la idea de la

Revista Iberoamericana, Vol. LXXXI, Núm. 252, Julio-Septiembre 2015, 837-846 ISSN 0034-9631 (Impreso)

ISSN 2154-4794 (Electrónico) 
adaptación de la novela al cine (emblematizada por la colombiana María del Rosario que finge ser la actriz mexicana Lupe Vélez que desempeñaría el papel de Alicia); entre otros.

En su estudio sobre la parodia en La otra selva, Natalia Crespo pone de relieve, acertadamente, la aparición de la voz de Alicia en el texto, una estrategia discursiva con la cual se lleva a cabo una continuación del intertexto. Alicia reanuda y transforma la historia de La vorágine escribiendo en plena selva mientras huyen de los apestados para evitar el contagio. De este modo se articula una perspectiva femenina de la que carece la obra original, tal como plantea Crespo: "La otra selva coloca como central al personaje antes marginal de Alicia y, al re-jerarquizar a la mujer, propone un nuevo tratamiento ideológico para los géneros" (291). Teniendo en cuenta la importancia de que Alicia cobre voz propia, lo que queremos resaltar aquí es la manera en que su voz se inscribe en el texto. Es Rivera, a través del autor Salazar, obsesionado con los personajes de su primera novela, quien le da voz: “¡Ah! ¿Es Alicia? ¿Quieres hablar a través de mí? Sí, hazlo, continúa, con tu voz, sí, con tu voz. Yo sólo escribiré, yo seré un mero vehículo de tu palabra, de tu mirada, de tu sentir" (Salazar 99). Al final de la novela, la narración se focaliza en el periodista, quien anda buscando a Rivera en el hospital: "Los gritos de la enfermera y los empujones de hierro de los guardias me alejaron de la voz de Alicia y me dejaron a solas con la historia que ahora intento concluir" (199). El impulso metaficticio y la autorreferencialidad predominan en la obra, incluso en lo que se refiere a la reivindicación de la voz de Alicia.

Mientras que lo que prevalece en La vorágine y se intensifica posteriormente en La otra selva es la polifonía y el entrecruzamiento de voces, en las obras de Vargas Vila - desde sus novelas y ensayos hasta sus diarios secretos- se abarca una extrema modificación del uso aceptado de mayúsculas y puntación, una sintaxis alterada, neologismos, palabras extranjeras y referencias al latín y a la antigüedad clásica, entre otros elementos. González Espitia plantea que la fragmentación textual producida por este uso insólito del lenguaje sugiere un constante deseo inalcanzado de completarse y refleja una sociedad que carece de unidad: "In his literary production, heterodoxy must penetrate the very manner in which it is inscribed: a stylistically degenerate text on the page is the reflection of a socially degenerate text in reality" (82). Asimismo el crítico postula que el uso idiosincrático del lenguaje de Vargas Vila en su momento constituía precisamente la plataforma desde la cual se revelaban su brillantez y singularidad (88). Así, a lo largo de La semilla de la ira, el Vargas Vila ficcionalizado proporciona continuas afirmaciones de su propio "genio" y se van intercalando sus reflexiones acerca de la libertad, la rebeldía, el arte y diferentes cuestiones filosóficas. El protagonista de Triviño Anzola declara que "[1]a originalidad ha sido mi consigna y la aplico en todos los aspectos de mi vida" (22); además, se jacta de ser "el más célebre de los escritores en lengua castellana" (74) y, comparándose con Darío y Almafuerte, señala que "ninguno de ellos fue tan lejos en su deseo de transgresión como yo; ninguno de ellos fue tan

Revista Iberoamericana, Vol. LXXXI, Núm. 252, Julio-Septiembre 2015, 837-846 ISSN 0034-9631 (Impreso)

ISSN 2154-4794 (Electrónico) 
irreverente con las leyes de gramática y de la moral como yo; ninguno de ellos despertó las pasiones de mis libros" (74).

Adiferencia de los estudiosos que postulan que Vargas Vila figura entre los precursores de la vanguardia, por la experimentación textual que caracteriza sus obras, Triviño Anzola lo considera más bien un escritor modernista malogrado, tal como señala en una entrevista: "él no puede ser fiel [a la poética modernista] porque la destroza malamente en frases recortadas con violencia. Él está violentando la lengua, rebelándose contra la sintaxis, queriendo ser innovador, pero fracasa, porque resulta afectado" (Díaz Ruiz 186). El proyecto de la autora consiste en imponerle al intertexto "una forma que viaja a través del idioma de todos y en el que se expresan nuestros sentimientos" (Díaz Ruiz 186). A diferencia de la fuerza centrífuga que rige la novela de Salazar e informa su poética de la novela, una fuerza centrípeta subyace en La semilla de la ira; en otras palabras, Triviño Anzola intenta unificar la fragmentación que define la escritura de Vargas Vila al montar una narración en torno a retazos extraídos de sus obras. El objetivo principal de la escritora bogotana radica en "humanizar al personaje, intentar comprender en qué consistían sus quejas y sus dolores. Cuando uno se acerca a la persona, la está desmitificando" (Díaz Ruiz 186).

A lo largo de La semilla de la ira va surgiendo una disonancia entre la narración, impulsada por el anhelo de desmitificar la figura de Vargas Vila, y la noción de la estética que va proclamando el protagonista: "En cuanto a los rebaños de letrados, quería provocarlos con mis violaciones al canon, demostrarles cuán ajena me era la tradición y cuánta hilaridad me causaba la autosuficiencia con la que pretendían juzgarme" (35). Triviño Anzola intenta desempeñar dos funciones simultáneamente: por un lado, asume una postura documentalista ante la vida y obra del escritor -Díaz Ruiz, por ejemplo, equipara La semilla de la ira a "una segunda tesis doctoral, sui generis" (187). Por el otro, la autora procura imitar la voz del escritor exiliado, una exigencia ineludible del género autobiográfico que ella ha optado por ficcionalizar. En La semilla de la ira se reproduce el monologismo que predomina en las obras de Vargas Vila, por ejemplo, pero se disminuye la oralidad que suele predominar en éstas. En otras palabras, la voz narrativa que se suele oír en los textos vargasvilescos, que se asemeja a la de un orador eclesiástico (Gómez Ocampo 82), apenas suena aquí. Asimismo, a diferencia del Vargas Vila que desprecia a los "gramáticos hirsutos", "estos eunucos, guardadores del serrallo léxico" (Ibis 26), y que se jacta de su rebeldía lingüística, el protagonista de Triviño Anzola escribe una prosa fluida, ceñida a las normas de la gramática castellana.

Según la definición básica que proporciona Linda Hutcheon, la parodia es la repetición de un discurso codificado mediante una trans-contextualización irónica con distancia crítica, la cual marca la diferencia más que la semejanza (32). En La semilla de la ira la función paródica es menor. La diferencia marcada entre texto e intertexto consiste, sobre todo, en la domesticación del lenguaje violentado de Vargas Vila que venimos señalando. La semejanza entre los dos, en cambio, estriba en un proceso de

Revista Iberoamericana, Vol. LXXXI, Núm. 252, Julio-Septiembre 2015, 837-846 ISSN 0034-9631 (Impreso)

ISSN 2154-4794 (Electrónico) 
asimilación; no se trata tanto de una trans-contextualización sino más bien de un intento de reinscribir la figura de Vargas Vila en el archivo abierto de aquel entonces. De ahí el afán totalizante que subyace en el texto por reconstruir el ámbito cultural e intelectual en el cual se movía el escritor colombiano. Se proporciona en la novela un cuadro del período mediante una serie de instantáneas de los lugares que visitaba, las ciudades en las que residía el autor y la presentación de un vasto elenco de personajes -escritores, artistas, políticos y otras figuras históricas así como algunos de los personajes ficticios de sus obras-con los cuales Vargas Vila entraba en diálogo, ya sea directa o indirectamente. Además, al asumir la voz de Vargas Vila, con el fin de desmitificarlo, Triviño Anzola proporciona explicaciones y pormenores de su misoginia, sus prejuicios, su sexualidad y los escándalos y calumnias que siempre seguían a la zaga del escritor.

La ironía que surge de La semilla de la ira no parece ser deliberada. Esta particularidad resta valor a la noción de una función paródica en la obra ya que tal parodia depende, en cierta medida, de una intencionalidad. Esta característica se relaciona con una paradoja principal de la parodia que Hutcheon describe como una especie de transgresión autorizada de las normas, recurriendo al análisis del carnaval de Bakhtin:

This paradox of legalized though unofficial subversion is characteristic of all parodic discourse insofar as parody posits, as a prerequisite to its very existence, a certain aesthetic institutionalization which entails the acknowledgement of recognizable, stable forms and conventions. (Hutcheon 74-75)

En La semilla de la ira se resalta la transgresión ideológica y política de Vargas Vila -su postura anti-regeneracionista y anticlerical, su oposición a las tiranías y su vehemente lucha por la libertad-mientras que al mismo tiempo se reprime su transgresión estética en la narración. No sobra señalar aquí que esta ironía no deliberada será percibida sólo por los lectores que conocen el intertexto de la misma manera en que se percibe la disonancia del texto mencionada anteriormente. Los lectores que desconocen el intertexto, en cambio, estarán ante una reconstrucción histórica de la vida y obra de un autor enigmático y la lectura de un vasto entramado transatlántico de la época.

En este sentido, se puede decir que La semilla de la ira, como un texto no paródico o hasta anti-paródico, funciona como obra ficticia en la medida en que el público lector desconozca el intertexto. La otra selva, en cambio, como novela sumamente paródica, abarca una trans-contextualización irónica que-para que funcione plenamente-exige del lector una triple competencia: lingüística, retórica e ideológica. ${ }^{5}$ Ahora bien, en lo que se refiere a estas dos reconfiguraciones del archivo, la clave está en el desdoblamiento de

Hutcheon plantea lo siguiente respecto a esta triple competencia: "It has been argued that irony requires of its readers a triple competence: linguistic, rhetorical or generic, and ideological" (94).

Revista Iberoamericana, Vol. LXXXI, Núm. 252, Julio-Septiembre 2015, 837-846 ISSN 0034-9631 (Impreso) 
cada autor archivista. Desdoblada como Vargas Vila, Triviño Anzola produce un libro que se pierde en la brecha entre biografía y autobiografía ficcionalizada, entre el anhelo de simular la voz de Vargas Vila y al mismo tiempo de subyugar su rebeldía estética. Al desdoblarse como el periodista espía de La otra selva -inmigrante colombiano en la selva neoyorquina- Salazar agudiza el enmarañamiento narrativo de La vorágine, apuntando a la entropía, e intensifica la experimentación estética del intertexto atravesando períodos históricos, géneros literarios y registros lingüísticos. El papel del lector ante este texto es distinto: tal como señala Jaime Alejandro Rodríguez, "[1]a acción de bricolage aquí plantea un continum [sic]: no sólo el autor y los personajes lo juegan, también el lector se ve impelido a convertirse en bricoleur" (76). Claramente, al lector que no conozca La vorágine y los avatares de Arturo y Alicia, La otra selva le resultará extremadamente hermética.

Para concluir, cada novela termina según la lógica interna de su estética. Al final de La semilla de la ira hay una especie de transmutación del autor, quien ahora sobrevuela el mundo convertido en un cóndor solitario que guarda un mensaje de paz y sigue con su canto de la libertad. La otra selva, a su vez, acaba con el periodista perdido en su propio laberinto de sucesos, recuerdos y textos. En un momento anterior, el periodista se dirige directamente a Rivera: "Al final, poeta, acabamos en lo mismo: usted, prisionero de sus personajes, y yo, esclavo de unos hechos que ocurrieron hace mucho tiempo. Al final, los dos acabamos tratando de escribir el mundo, porque nos fue imposible poseerlo" (101).

\section{Obras Citadas}

Borges, Jorge Luis. El hacedor. Madrid: Alianza, 1997.

Crespo, Natalia. "La otra selva de Boris Salazar como parodia de La vorágine". Revista de Estudios Hispánicos 42 (2008): 279-299.

Díaz Ruiz, Fernando. "Entrevista a Consuelo Triviño: reivindica la obra del semiolvidado Vargas Vila, negando similitudes con la de Fernando Vallejo". Iberoamericana: América Latina-España-Portugal 10/40 (2010): 185-189.

García Sánchez, José María. "La representación del sujeto en 'La novela corta’ de José María Vargas Vila”. Tesis de doctorado. Arizona State University, 1996.

Gómez Ocampo. Entre María y La vorágine: la literatura colombiana finisecular (18861903). Bogotá: Fondo Cultural Cafetero, 1988.

González Espitia, Juan Carlos. On the Dark Side of the Archive: Nation and Literature in Spanish America at the Turn of the Century. Lewisburg: Bucknell UP, 2010.

Guerrieri, Kevin G. Palabra, poder y nación: la novela moderna en Colombia de 1896 a 1927. Ciudad Juárez, México: Universidad Autónoma de Ciudad Juárez, 2004.

Hutcheon, Linda. A Theory of Parody: The Teachings of Twentieth-Century Art Forms. Nueva York: Methuen, 1985.

Revista Iberoamericana, Vol. LXXXI, Núm. 252, Julio-Septiembre 2015, 837-846 ISSN 0034-9631 (Impreso)

ISSN 2154-4794 (Electrónico) 
Molloy, Silvia. "Contagio narrativo y gesticulación retórica en La vorágine”. La vorágine: textos críticos. Montserrat Ordóñez, ed. Bogotá: Alianza Editorial Colombiana, 1987. 489-509.

Moreno-Durán, R. H. "Las voces de la polifonía telúrica". La vorágine: textos críticos. Montserrat Ordóñez, ed. Bogotá: Alianza Editorial Colombiana, 1987. 437-452.

Neale-Silva, Eduardo. Horizonte humano: vida de José Eustasio Rivera. México: Fondo de Cultura Económica, 1960.

Ordóñez, Montserrat. Introducción. La vorágine. José Eustasio Rivera. Madrid: Cátedra, 2005. 9-58.

ed. La vorágine: textos críticos. Bogotá: Alianza Editorial Colombiana, 1987.

$\overline{\text { Pineda }}$ Botero, Álvaro. Estudios críticos sobre la novela colombiana, 1990-2004. Medellín: Fondo Editorial Universidad EAFIT, 2005.

Rivera, José Eustasio. La vorágine. Montserrat Ordóñez, ed. Madrid: Cátedra, 2005.

Rodríguez, Jaime Alejandro. Posmodernidad, literatura y otras yerbas. Bogotá: Pontificia Universidad Javeriana, 2000.

Salazar T., Boris. La otra selva. Bogotá: Tercer Mundo Editores, 1991.

Triviño Anzola, Consuelo. La semilla de la ira. Bogotá: Editorial Planeta Colombiana, 2008.

Vargas Vila, José María. Diario (de 1899 a 1932). Y la increíble historia de unas memorias codiciadas. Raúl Salazar Pazos, ed. Barcelona: Áltera, 2000. Ibis. Juan Carlos González Espitia, ed. Bogotá: Panamericana, 1998. 